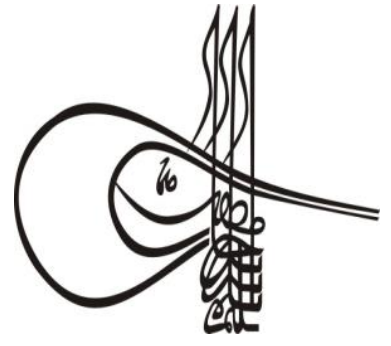

Received/Geliș: 20.11 .2019
Tutkigh Studies

\section{Social Sciences}

Volume 14 Issue 6, 2019, p. 3383-3400

DOI: 10.29228/TurkishStudies.39837

ISSN: 2667-5617

Skopje/MACEDONIA-Ankara/TURKEY

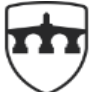

INTERNATIONAL BALKAN UNIVERSITY

EXCELLENCE FOR THE FUTUR IBU.EDU.MK

Research Article / Araștırma Makalesi

ArticleInfo/MakaleBilgisi

VAccepted/Kabul: 31.12 .2019

Gor Report Dates/Rapor Tarihleri: Referee 1 (31.12.2019)-Referee 2 (04.12.2019)

This article was checked by iThenticate.

\title{
SOSYODEMOGRAFİK DEĞİŞKENLER VE NAMUS ADINA KADINA UYGULANAN SSIDDETE YÖNELIK TUTUM: ÜNİVERSİTE GENÇLİĞİ ÜZERİNE BİR ARAŞTIRMA
}

\author{
Meral ÖZTÜRK* - Olcay TİRE
}

\begin{abstract}
ÖZ
Kadına yönelik şiddet, hem dünyanın hem de Türkiye'nin en önemli toplumsal sorunlarından biridir. Ataerkil kültürün birürünü olan kadına yönelik şiddetin sözde nedenlerinden birisi "namus" olgusudur. Namus kültürünün egemen olduğu toplumlarda kadınlar namus adına sözel, psikolojik, cinsel ve fiziksel şiddete uğramakta hatta namus cinayetlerine kurban gitmektedirler. Namus adına kadına uygulanan şiddete yönelik tutumların sosyodemografik değişkenlerden etkileneceği varsayımından hareketle bu araștırmanın amacı gelecekte toplumsal yapının belirleyicileri ve yön vericileri olacak olan üniversite öğrencilerinin namus adına kadına uygulanan şiddete yönelik tutumlarının cinsiyet, okunulan alan, sınıf düzeyi, ailenin gelir düzeyi, gelinen bölge, anne-baba eğitim düzeyi gibi sosyo-demografik faktörlere göre farklılaşıp farklılaşmadığını ortaya koymaktır.

Araștırma Sivas Cumhuriyet Üniversitesi'nin farklı bölümlerinde okuyan tabakalı örnekleme ve kolayda örnekleme teknikleri ile belirlenen 662 kişi ile yürütülmüştür. Araştırmada kişisel bilgi formu yanında Issık ve Sakallı-Uğurlu (2009) tarafından geliştirilen Namus Adına Kadına Uygulanan Şiddete Yönelik Tutum Ölçeği (NKUŞTÖ) kullanılmıştır. Verilerin analizi ikili gruplar için bağımsız örnekleme $t$ testi, üç ve daha fazla gruplar için tek yönlü varyans analizi ile yapılmıştır. Elde edilen bulgulara göre genel olarak öğrencilerin namus adına kadına uygulanan şiddeti onaylamadıkları ancak erkekler, sağlık ve fen bilimleri alanında okuyanlar, birinci ve ikinci sınıf ögrencileri ile
\end{abstract}

Dr. Öğr. Üyesi, Sivas Cumhuriyet Üniversitesi, Edebiyat Fakültesi, Sosyal Hizmet Bölümü, E-posta: mrozturk@cumhuriyet.edu.tr

Dr. Öğr. Üyesi Munzur Üniversitesi, Edebiyat Fakültesi, Sosyoloji Bölümü, E-posta: olcaytire@ gmail.com 
annesi okur-yazar olmayan öğrenciler namus adına kadına uygulanan şiddete daha olumlu bakmaktadır. Gelir düzeyi, gelinen bölge ve baba eğitim düzeyine göre gruplar arasında farklılık yoktur.

Anahtar Kelimeler: Namus, Kadın, Şiddet, Üniversite Gençliği

\title{
SOCIODEMOGRAPHIC VARIABLES AND ATTITUDES TOWARDS VIOLENCE AGAINST WOMEN IN THE NAME OF HONOR: A RESEARCH ON UNIVERSITY YOUTH
}

\begin{abstract}
Violence against women is one of the most important social problems in Turkey and in the rest of the world. One of the factors resulting in violence against women is supposedly the "honor" phenomenon, a product of patriarchal culture. In societies where honor culture is dominant, women are subjected to verbal, psychological, sexual and physical violence in the name of honor, and they even become victims of honor killings. Based on the assumption that attitudes towards violence against women in the name of honor are affected by sociodemographic variables, this study analyzes whether the attitudes of university students, who shall become the determinants and guiding agents of social structure in the future, differ in terms of socio-demographic factors such as gender, the area of study, class level, family income level, region of origin, and parental educational level.

The study was carried out with 662 individuals who were determined by stratified and convenient sampling techniques in various departments of Sivas Cumhuriyet University. In addition to a personal information form, the Scale of Attitude towards Violence against Women in the Name of Honor (NKUŞTÖ), developed by Işık and Sakall1-Uğurlu (2009), was used in the study. The analysis of the collected data was conducted through independent samples t test for two groups and one way analysis of variance for three and more groups. According to the findings, in general, university students do not approve of violence against women in the name of honor; however, male students,students studying at health and science departments, the 1st and 2nd grade students, and students whose mother is illiterate exhibite more positive views on violence against women. Dissimilarly, no differences according to their level of income, region of origin and the education level of father has been found among the groups.
\end{abstract}

\section{STRUCTURED ABSTRACT}

\section{Introduction}

Violence that is committed in the name of honour is frequently seen in societies, formed around moral or/and patriarchal norms. (Dietrich \& Schuett, 2013; Grzyb, 2016).In such cultural structures honour conveys different meanings for men and women While the term 'virtue' stands for honesty, professional reliability and preserving family name in men's world, for women it stands for 'sexual morality' that is 'virginity' and is affiliated with true commitment to men. (Aksoy and 
Y1lmaz-Vefikuluçay, 2019: 3;Bourdieu, 2016). A virtuous woman is the one who has no sexual activities until she is married and is supposed to preserve herself for her husband. A sexual activity does not only stand for an intercourse but also refers to some behaviours such as inappropriate clothing, social interaction with a man without the permission of family, walking alone with a man hand in hand, kissing or flirting with him (Sallan-Gül and Altındal, 2015: 172). For a woman, being virtuous requires seeing no men outside the family without supervision, fulfilling her parental/maternal, wife, filial and bridal duties (Sen, 2014: 64). Virtue/honour is perceived accordingly with age, gender, educational background, habitat etc. and it finds its real meaning. (see Berrin Bulut and Ylldırım, 2018; Dadashzadeh, 2016; Iş1k, 2008; Kardam, 2005).

Perception of virtue is shaped by socio demographic factors, thus it is possible to say these factors can also influence a violent act against women in the name of honour. Based on this hypothesis, this study aims to reveal if violent acts or attitudes against women among college students vary with gender, class, income level, precollege setting, educational background of parents.

\section{Methodology}

Survey method is used in this research. Research population includes college students from various faculties of Cumhuriyet University, Sivas. The sample consists of 662 individuals, selected from the faculties by 'stratified sampling method'. In this study, layer unit was based on 'major field of studies'. In this context three layers were identified as health, social and numerical sciences. Faculty of Letters and Faculty of Education from social sciences, Faculty of Health Sciences and Faculty of Pharmaceutical Sciences, Faculty of Science from numerical sciences are added to the sampling.

A personal information form have been used to identify the socio demographic characteristics of participants. Additionally, 'A Scale of Attitudes Towards Violence in the Name of Honour Against Women' have been utilized. The scale developed by Issik and Sakallı (2009) include 14 articles which consist of six point likert scale answers. The high scores obtained from the scale reflect a positive attitude towards violence in the name of honour against women.

\section{Result}

First, findings obtained from the research showed that attitudes of students against violence committed in the name of honour against woman were low. Işık and Sakall1-Uğurlu (2009) clarifies this result with the tendency of students to reply to such questions in a socially accepted manner.

Second, students studying at social sciences faculties were less approved violenceagainst women in the name of honor than students teaching at numerical and health sciences.

Third, compared to women, violence committed against women in the name of honour are approved more by men. This finding is consistant with the literature (Berrin Bulut and Yıldırım, 2018; Çalık, 2017; Demirel vd., 2019; Issik, 2008; Kaya and Turan, 2018; Sakall1Uğurlu ve Ulu, 2003). Tendency of men to approve violence against

\section{Turkish Studies - Social Sciences}

Volume 14 Issue 6, 2019 
women in the name of honour more could be stem from different socializing process between men and women (see Sakallı and Akbass, 2013).

Fourth, this research revealed that the higher the class level was the lower the approval level toward violence against women under cover of honour gets. This finding indicates that the longer the duration of college education the more the critical approach to social norms and morals increases along with questions concerning the terms 'virtue' and 'honour', thus the role of gender mainstreaming is embraced more.

Fifth, attitudes of students toward violence against women in the name of honour do not differ in accordance with their income level. This result is probably related to the structure of the question asking the income status of students. In the study, the participants were asked to answer the questions about their income level by ticking up one of low income, middle income and high income options. It is possible that the participants might have answered the questions in a subjective manner (Öztürk, 2015).

Sixth, attitudes of students towards violence against women in the name of honour do not differ with regard to where they come from. This is probably this is probably due to the fact that most of the students grew are from urban centres. While 62 percent of the sample (410 individuals) stated they were born and raised in city centres, 38 percent of it (252 individuals) declared they came from small towns, districts and villages.

Finally, mother's educational level decreased approval levels of students towards violence against women in the name of honour but there were no such differentiations between groups in terms of fathers' education level. This fact reveals the important role of a mother in a child's education. Within Turkish family structure, mothers have the primary role in child raising (Özensel, 2004). Hence, the education level of a mother notably determines the social roles and values children will internalise. Studies on this matter revealed that unlike the majority of society, mothers with higher education level have a more egalitarian perception of virtue. They are more responsive to violence against women and have a more critical approach to gender roles (see Cirhinoğlu and Şenel, 2017; Çağlayan, 2019; Güneri Er and Şen, 2018; Gürsoy, 2009; Gürsoy and Arslan-Özkan, 2014; Kodan-Çetinkaya, 2013; Zeyneloğlu, Kısaoğlu and Yılmaz, 2013). youth.

Keywords: Attitude, Honor, Violence against women, University

\section{Giriş}

Kadına yönelik şiddet, kadının kamusal ve özel alanda baskı altına alınmasına ve özgürlügünün kısıtlanmasına neden olan fiziksel, cinsel, duygusal, ekonomik vb. şiddet şeklinde kendini gösteren cinsiyete dayalı bir insan hakları ihlalidir (Sallan Gül, 2014: 181). Dünya Sağlık Örgütü (DSÖ) tarafindan 2013 yılında yayımlanan rapora göre, dünyada kadınların \%35'i erkekler tarafindan çeşitli şekillerde şiddete uğramaktadırlar (https://insamer.com/tr/kadina-yonelik-siddet). Kadına yönelik şiddet olaylarında suç failleri genellikle kadının mevcut eşi, boşanmak üzere olduğu eşi, sevgilisi veya baba, erkek kardeş gibi yakın aile üyeleridir (Yüksel Oktay, 2015: 61). Benzer bir

\section{Turkish Studies - Social Sciences}

Volume 14 Issue 6, 2019 
tablo Türkiye için de geçerlidir. "2014 Türkiye'de Kadına Yönelik Aile İçi Şiddet Araştırması" sonuçlarına göre, kadınların \%36'sı eşi veya sevgilisi tarafından fiziksel şiddete, \%44'ü duygusal şiddete maruz kalmaktadır (Berber, 2016, 254-255).

Kadına yönelik şiddet; kadın cinayetleri, kadın intiharları, fiziksel şiddet, erken ve kendilerine uymayan kişilerle zorla evlendirilme, çok çocuk doğurmaya zorlanma, çok eşli evlilik, taciz-tecavüz, eve hapsetme, okula ve işe gönderilmeme şeklinde ortaya çıkabilmektedir (Sallan Gül, 2014: 181; Sakall1-Uğurlu ve Akbaş, 2013: 84; TBMM Komisyon Raporu, 2006). Kadınlar bu tür şiddetlerle, ataerkil kültürün hâkim olduğu toplumsal yapılarda daha çok karşılaşmaktadırlar (Dietrich ve Schuett, 2013; Grzyb, 2016). Ataerkil yapı tarım toplumuna geçişle başlayan yapıya işaret etmektedir. Engels (1990) artı ürünün olmadığı ilkel komünal toplumlarda, kadınların toplumsal konumlarının erkeklerden düşük olmadığını hatta doğurganlık özelliklerinden dolayı erkeklerden üstün olduğunu öne sürmektedir. Ancak yerleşik yaşam, erkeğin fiziksel gücünü kullanarak zenginleşmesini sağlamış, kadınların toplumsal konumlarını yitirmelerine yol açmıştır. Buradan yola çıkarak Engels ataerkil sistemi, toplumsal ve ekonomik bir yapılanma olarak tanımlamaktadır. Bu sistemde erkekler mal varlıklarının yasal evlatlarına kalmasını sağlamak amacıyla kadının cinselliğini kontrol altına alma davranış1 geliştirmişlerdir. $\mathrm{Bu}$ durum kaptalist sistemle daha da meşrulaş̧ırılmış, kadın güç ve zenginliğin kuşaklararası geçişinde yalnızca aracı rolü üstlenmiştir (Mies, 2012; Sev'er ve Yurdakul, 2001; Yaman, Öztürk ve Dedeoğlu; 2010).

Ataerkil kültür, namus konusunda da cinsiyetler arası hiyerarşik yapıya yol açmıştır. Çünkü ataerkil yapının ürettiği toplumsal cinsiyet rolleri, kadınlar ve erkekler için uygun olan farklı kişilik özelliklerini ve davranışlarını belirlemiştir. Erkeğe uygun olduğu varsayılan davranışlar erkeksi (maskülen), kadınlara uygun görülen davranışlar kadınsı (feminen) cinsiyet rolleri olarak tanımlanmıştır (Dökmen, 2010: 31). Kadınsı cinsiyet rolü bağımlı olmayı, itaat etmeyi, duygusal olmayı ve bakım emeğini içerirken erkeksi cinsiyet rolü bağımsı, güçlü, cesur, akılc1, statü sahibi olmayı ve zayıf olduğu düşünülen kadınları kontrol etme ve koruma görevini içermektedir. Ataerkil kültürlerde namus, kadın ve erkekler için farklı anlamlara gelmektedir. Erkekler için dürüstlük, güvenilirlik, ailenin şerefini koruma, karşı gelme, göze alma ve mücadele etme anlamında kullanılan namus, kadınlar için çoğunlukla "cinsel saflık", yani "bakirelik" anlamında kullanılmakta, erkeğe teslim olmayla ilişkilendirilmektedir (Aksoy ve Yılmaz-Vefikuluçay, 2019; Bourdieu, 2016). Bu tür kültürlerde erkeğin eşini, kızını, kız kardeşini, annesini gözetim ve denetim altında tutması, namusuna karşı herhangi bir zarar ya da risk durumunda güç ve şiddet kullanabilmesikabul edilebilir bir davranış olarak görülmektedir (Sakallı Uğurlu ve Akbaş; 2013; Sallan-Gül ve Altındal, 2015; Vandello, 2016; Vandello \& Cohen, 2003). Buna karşın n namusunu korumakla sorumlu iken kadınlar pasif birer aktör olarak namuslu kabul edilen davranış kurallarına uymak mecburiyetindedir (Kardam, 2005: 19). Namuslu kadın, evlenene kadar hiçbir cinsel eylemde bulunmayan ve evlendikten sonra da cinselliğini sadece kocasına sunan kadındır. Buradaki cinsel eylem sadece cinsel birliktelikleri değil; toplum kurallarına uygun olmayan şekilde giyinme, ailesi dışındaki bir erkekle refakatsiz konuşma, bir erkekle yalnız başına yürüme, tensel temas ve flört etme gibi davranışları içermektedir (Sallan-Gül ve Altındal, 2015: 172). Bunun yanında kadınlar için namuslu olmak; mahrem olan erkeklerle yalnızken buluşmamak, annelik görevlerini ve eş sorumluluklarını yerine getirmek, ebeveynlerine karşı kız ve gelin olarak görevlerini yerine getirmektir (Sen, 2014: 64). Ataerkil sistem, erkeğe kadına karşı bir üstünlük verirken, kadını erkeğin mülkü dolayısıyla erkekler tarafından kontrol edilecek ve korunacak bir nesne durumuna getirmekte (Ünsal-Atan, 2016: 70), kadınları sadece yakın aile fertlerinin değil aynı zamanda aşiret ve akraba çevresindeki bütün erkeklerin gözetimi ve denetimi altına sokmaktadır. Çünkü namus kavramı, erkeğin topluma kabul edilmesi açısından önemlidir. Erkeğin bu konudaki başarısızlığı, utanç duymasına ve statü kaybetmesine neden olmaktadır (Ünsal-Atan, 2016: 70). Dolayısıyla namus olgusu, kadını utanç erkeği ise onur ve/veya şeref değerleri çerçevesinde anlamlandırmaktadır. Kadın kendi cinselliğinden duyduğu utançla birlikte erkeğin namusunu korumakla sorumlu tutulurken, erkek kendi şerefi ve onuru için kadının namusunu şiddete

\section{Turkish Studies - Social Sciences}

Volume 14 Issue 6, 2019 
başvurmakta dahil olmak üzere denetlemekle sorumludur (Moritz, 2008;Yıldız, 2009: 98). Kadın namus kurallarını ihlal ettiğinde ya da ihlal ettiği düşünüldüğünde, kendisinin ve ailesinin özelliklede ailedeki erkeklerin namusu lekelenmiş sayılır. Namus bireysel bir kişilik özelliği olarak değil, kolektif kimliğin bir parçası olarak kabul edilir (Doğan, 2016: 13). Bu durumda, ataerkil sistemin normları gereği lekelenen namusun temizlenmesi ve yitirildiği düşünülen aile şerefinin ve saygınlığının tekrar kazanılması için kadına en ağırı ölüm olmak üzere namus temelli çeşitli cezalar uygulanır. Kadını bağımsız bir özne olarak görmeyen ataerkil toplumların kültürlerinde gelişen namus kuralları, kadınların hem özgürlüklerini kısıtlar hem de en temel hakları olan yaşama haklarını ellerinden alır. Kadınların yaşama haklarını ellerinden alan bu olguya namus cinayetleri denilmektedir. "Namus cinayeti" kavramını feministler kadına karşı şiddetin politik olduğunu göstermek için kullanmakta, bu şekilde kültürel ideolojinin nasıl suça dönüştüğünün altını çizmektedirler(Grewal, 2013). Namus cinayetleri kadınların varlığına yönelik cinsel şiddetin bir türüdür ve evrensel bir fenomendir (Akbaba, 2008: 336). Her ne kadar namus nedeniyle öldürülen kadınların sayıs1 tam olarak bilinmese de Birleşmiş Milletler Nüfus Fonu her yıl dünyada 5.000'den fazla kadının ailelerindeki erkekler ya da sevgilileri tarafindan namus nedeniyle öldürüldügünü tahmin etmektedir (Devers ve Bacon, 2010). Ancak kadın hakları savunucularına göre, bu sayı yılda ortalama 20.000 civarındadır. Bu durum birçok namus cinayetinin ortaya çıkmamasından ve kayıtlara geçmemesinden kaynaklanmaktadır. Çünkü aile üyeleri bu tür durumları intihar ya da kaza sonucu ölüm olarak bildirmektedirler (Aksoy ve YılmazVefikuluçay, 2019: 10-11). Türkiye, namus cinayetlerinin görüldüğü ülkelerden birisi olmasına karşın namus cinayetlerinin ülke içindeki yaygınlığını ortaya koyan resmi kayıtlara ulaşmak mümkün değildir. Bunun yanında mağdur ve faillerin özellikleriyle ilişkili sağlıklı resmi kayıtlara da ulaşılamamaktadır (Dinç ve Hotun-Şahin, 2009: 128). Türkiye'de namus cinayetleri bekâr bir kızın bir erkekle ilişkisi, evlenmeden bekaretini yitirmesi, bir erkekle özellikle evli bir erkekle kaçması, evlilik öncesi/dışı hamile kalması gibi nedenlerle işlendiği gibi evli veya bekâr bir kadının kaçırılması ve tacize uğraması, eşi dışında başka bir erkekle ilişki yaşaması, eşinden boşanmak istemesi ve başka bir erkekle kaçması da öldürülmesi için neden olarak görülmektedir (Kardam, 2005:29)

Namus kişilerin yaşı, cinsiyeti, eğitim durumu, yaşanılan yer vb. faktörlerin etkisi altında algılanıp, anlam bulmaktadır (bkz. Berrin Bulut ve Yıldırım, 2018; Dadashzadeh, 2016; Işık, 2008; Kardam, 2005). Namus olgusu, yukarıda da açıklandığı üzere daha çok aşiret ve akrabalık ilişkilerinin güçlü olduğu yerlerde önemlidir. Bunun yanında namus, kırdan kente göç etmiş olsa bile sosyal çevresini değiştirmeyip halen toplumsal değerlere bağlı olan kişilerde de yaşamın anlamı ve amacı olarak görülmektedir (Kardam, 2005: 62). Feodal ilişkilerin yanı sıra eğitimsizlik ve yoksullukta namus algısının şekillenmesinde temel belirleyici unsurlardandır (TBMM Komisyon Raporu, 2015: 67). Öztürk ve Demirdağ (2013: 124)'in Mardin cezaevinde namus davası nedeniyle mahkûm olan hükümlüler üzerinde yaptıkları çalışmaya göre; günümüzde ataerkil kültürün ürettiği cinsiyetçi namus anlayışına sahip olup namus cinayeti işleyenlerin büyük çoğunluğunu kırsal alanlarda ya da şehirlerin kenar mahallelerinde yaşayanlar ve sınıfsal açıdan alt sosyo-ekonomik tabakaya ait olanlar oluşturmaktadır. O halde, sanayileşme ve modernleşmenin getirdiği kent kültürünün ataerkil cinsiyet rollerinde, geleneklerde, göreneklerde; dolayısıyla bireylerin davranışlarında eşitlikçi toplumsal cinsiyet ilişkileri yönünde değişime neden olduğunu söyleyebiliriz. Çünkü bireyin doğduğu yerdeki toplumun sosyo-ekonomik yapısı, kadın ve erkeğe uygun görülen roller doğrultusunda büyümesini sağlar. Kentlerde kadınların eğitim, iş ve sosyal yaşama katılımlarının çoğalması, kadın-erkek arasındaki cinsiyetçi ayrımcılığın azalmasını sağlamaktadır. Bu ortamda sosyalleşen bireylerinde kadına ilişkin namus tutumlarının pozitif yönde geliştiği görülmektedir (Bkz. Güneri Er ve Şen, 2018: 264). Yine aile üyelerinin eğitim düzeyinin kişilerin namus algısını etkilediğini ortaya koyan pek çok çalışma vardır (Bkz. Pınar ve arkadaşları, 2008; Arıcı, 2011).

Namus algısı sosyo-demografik faktörlerden etkilendiğine göre namus adına kadına uygulanan şiddete yönelik tutumlarda sosyo-demograik özelliklerden etkilenebilir temel varsayımından hareketle bu çalışma üniversite gençliğinin cinsiyet, sınıf, gelir düzeyi, üniversiteden önce yaşanılan il, anne ve

\section{Turkish Studies - Social Sciences}

Volume 14 Issue 6, 2019 
baba eğitim düzeyi bakımından namus adına kadına uygulanan şiddete yönelik tutumlarının farklılaşıp farklılaşmadığını ortaya koymayı amaçlamaktadır. Araştırmada aşağıdaki hipotezler test edilecektir:

1. Gençlerin namus adına kadına uygulanan şiddete yönelik tutumları cinsiyetlerine göre farklılık göstermektedir. Ataerkil toplumsal yapının erkek ve kadınları namus konusunda farklı sosyalleşme sürecine tabi tutması, bu etkiyle yetişen erkeklerin toplumdaki güç ve hâkimiyetlerini kadının namusu üzerinden koruma içgüdüsü (Sakallı Uğurlu ve Akbaş; 2013) erkeklerin namus adına kadına uygulanan şiddete daha çok onay vereceklerini düşündürmektedir.

2. Gençlerin namus adına kadına uygulanan şiddete yönelik tutumları okudukları alana göre farklılaşmaktadır. Sosyal bilimler alanında okuyanların aldıkları derslerin içeriği gereği namusla ilişkili olarak daha eşitlikçi tutum benimseyecekleri (Çağlayan, 2019; Gürsoy, 2009) ve dolayısıyla sağlık ve fen fakültesinde okuyan öğrencilere kıyasla namus adına işlenen suçlara daha az onay verecekleri düşünülmektedir.

3. Gençlerin namus adına kadına uygulanan şiddete yönelik tutumları okudukları sınıf düzeyine göre farklılık göstermektedir. Eğitimin kadın ve erkeklerin sahip oldukları değerleri sorgulaması ve eleştirel düşünmeye yöneltmesi bunun sonucunda eşitlikçi namus anlayışını ortaya çıkarması üzerindeki etkisi (Güneri Er ve Şen, 2018) nedeniyle bu çalışmada sinıf düzeyi arttıkça namus adına kadına uygulanan şiddete onay verilmeyeceği düşünülmektedir.

4. Gençlerin namus adına kadına uygulanan şiddete yönelik tutumları gelir düzeyine göre farklılık göstermektedir. Gelir düzeyinin eğitime katılım üzerindeki etkisi (Tomul, 2007) eğitimin de eşitlikçi namus anlayışını ortaya çıkarması (Güneri Er ve Şen, 2018) nedeniyle gelir düzeyi yüksek olanların düşük olanlara kıyasla namus adına kadına uygulanan şiddete yönelik tutumlara onay vermeyecekleri düşünülmektedir.

5. Gençlerin namus adına kadına uygulanan şiddete yönelik tutumları üniversiteye gelmeden önce yaşadıkları bölgeye göre farklılık göstermektedir. Kırsal yerleşim birimlerinde, aşiret ve akrabalık ilişkilerinin ve feodal ilişkilerin güçlü olduğu yerlerde ataerkil toplumsal yapının hâkim olması nedeniyle namus anlayışının daha katı olacağı (Bilgili ve Vural, 2011; Kardam, 1996) düşünüldügünden özellikle bu tür yapıların güçlü olduğu Güneydoğu ve Doğu Anadolu Bölgeleri'nde bulunan illerde yaşayanların namus adına kadına uygulanan şiddete yönelik tutumlarının daha olumlu olacağı varsayılmaktadır.

6. Gençlerin namus adına kadına uygulanan şiddete yönelik tutumları ebeveyn eğitim düzeyine göre farklılaşmaktadır. Ailenin çocuğun sosyalleşmesinde, toplumsal değerleri ve normları içselleştirmesindeki önemli rolü bilinmektedir. Bu süreçte ebeveynlerin eğitim düzeyinin, çocuğun gelişimini biçimlendirdiği (Çağlayan, 2019) varsayımından hareketle bu çalışmada anne-baba eğitim düzeyinin yükselmesiyle çocuğun daha eşitlikçi namus anlayışı ile yetiştirileceği (Arıc1, 2011) bunun sonucu olarak namus bahanesiyle kadınlara yönelik şiddete onay vermeyecekleri düşünülmektedir.

$\mathrm{Bu}$ araştırmanın birkaç açıdan literatüre katkı sunacağı düşünülmektedir. Birincisi, namus ve namus adına kadına uygulanan şiddete yönelik tutumları ölçmek amacıyla yapılan araştırmalar oldukça sınırlıdır (Demirel, Kaya, Ertekin Pınar, Değerli ve Gökmen, 2019) ve bu çalışmalar genellikle psikologlar (Berrin Bulut ve Yıldırım,2018; Sakallı-Uğurlu ve Akbaş, 2013; Sakallı-Uğurlu ve Ulu, 2003; Işık ve Sakallı-Uğurlu, 2009) ve sağlı çalışanları (Demirel vd., 2019; Güneri Er ve Şen, 2018) tarafından yapılmıştır. Bu çalışma ise konuyu sosyolojik bakış açısıyla ele almaktadır. İkincisi insanların davranışlarını etkileyen en önemli unsurlardan birisi inançları ve tutumlarıdır (Bkz. Khan,2018). Kişilerin namusla ilişkili tutumları namusa yönelik şiddete bakışlarını etkilemektedir (Iş̧k ve Sakallı- Uğurlu, 2009). Benzer şekilde namus adına kadına yönelik şiddetle ilişkili tutumlarda hem bu tür şiddete maruz kalan kadınların hem de namus için kadına uygulanan şiddete doğrudan/dolaylı şahit olanların tepkilerini belirleyecektir. Eğer bir kişi namus için kadına uygulanan şiddete olumsuz tutum gösteriyorsa, bu mağdurları korumak için çaba göstermesinde itici güç olabilir.

\section{Turkish Studies - Social Sciences}

Volume 14 Issue 6, 2019 
Bununla birlikte bu istismar türünü onaylamayan mağdurların kendilerini koruma ve yardım arama çabaları daha fazla olabilir (Khan,2018). Üçüncüsü bu çalışma üniversite öğrencileriyle gerçekleştirilmiş̧ir. Üniversite öğrencilerinin konuyla ilişkili tutumlarını öğrenmek önemlidir çünkü üniversite gençliği ülkenin geleceğini şekillendirme, geleceğin toplumsal yapısını belirleme, toplumsal yapıya yön verme, değişimi tetikleme ve sağlama hususunda özel öneme sahiptir. Bu grubun namus adına kadına uygulanan şiddete yönelik tutumu gelecekteki Türkiye'nin toplumsal yapısı hakkında ipucu verecektir. Son olarak Türkiye gibi ülkelerde yaygın görülen namus adına kadına uygulanan şiddete yönelik toplumun bakışını incelemek ve bu bakışı etkileyen psikolojik ve sosyal faktörleri ortaya koymak; bu sorunu çözmekle sorumlu devlet yöneticilerine sorunun çözümünde nasıl bir politika izlemeleri gerektiği hususunda yardımcı olabilir.

\section{Araştırmanın Yöntemi}

$\mathrm{Bu}$ araştırma nicel araştırma yöntemiyle gerçekleştirilmiş betimsel bir araştrmadır.

\section{Araştırmanın Evren ve Örneklemi}

Araştırmanın evrenini Sivas Cumhuriyet Üniversitesi'nin çeşitli fakültelerinde eğitim gören öğrenciler oluşturmaktadır. Araştırmanın örnekleminin seçiminin ilk aşamasında "tabakalı örnekleme tekniği” kullanılmıştır. Tabakalı örnekleme tekniği evreni bir veya birkaç özelliği bakımından benzer alt gruplara ayırmak için kullanılmaktadır. Bu teknikle evrendeki her birim örnekleme girme şansını elde etmektedir (Yıldırım ve Şimşek, 2013: 133). Bu çalışmada tabaka birimi olarak "eğitim görülen alan" kullanılmıştır. Bu kapsamda sağlık bilimleri, sosyal bilimler ve sayısal bilimler olmak üzere üç tabaka belirlenmiştir. Sosyal bilimler alanında Edebiyat Fakültesi ve Eğitim Fakültesi, sağlık bilimleri alanında Sağlık Bilimleri Fakültesi ve Eczacılık Fakültesi, sayısal bilimler alanında Fen Fakültesi örnekleme dâhil edilmiştir. Ardından kolayda örnekleme yöntemi ile ulaşılması kolay olan öğrencilerden 700 kişiye anket uygulaması yapılmıştır. Ancak analiz için uygun olmayan anketlerin çıkarılmasıyla kalan 662 kişi araştırmanın örneklemini oluşturmuştur.

\section{Araştırmanın Veri Toplama Araçları}

Araştırmada katılımcıların sosyo-demografik özelliklerinin ortaya koymak amacıyla kişisel bilgi formu ile konuyla ilgili çalışmalarda yaygın biçimde kullanılan "Namus Adına Kadına Uygulanan Şiddete Yönelik Tutumlar Ölçeği” kullanılmıştır. Işık ve Sakalli-Uğurlu (2009) tarafindan geliştirilen ölçekte 6'lı likert tipi cevaplar içeren 14 madde yer almaktadır. Bu ölçekte 1=hiç katılmıyorum, 6 ise çok katılıyorum anlamına gelmektedir. Ölçekte 7 madde ters yönlü kodlanmaktadır. Ölçek tek faktörlü bir yapıya sahip olup toplam varyansın \%47,45'ini açıklamaktadır. Ölçekten elde edilen puanın yüksekliği namus adına kadına yönelik şiddete ilişkin olumlu tutumu yansıtmaktadır. Ölçeğe uygulanan doğrulayıcı faktör analizi ölçeğin geçerliliğini ortaya koymuştur. Ölçeğin Cronbach Alfa iç tutarlılık katsayısı 0,83'dir.

\section{Bulgular}

\section{Örneklemin Sosyo-Demografik Özellikleri}

Araştırmaya $431(\% 65,1)$ kadın, 231(\%34,9) erkek katılmıştır. Ankete katılan kız öğrenci sayısı erkek öğrenci sayısının iki katıdır. Bunun nedeni örneklemin seçildiği fakültelerde eğitim gören toplam 13244 öğrencinin yaklaşık \%65'inin (kız öğrenci sayısı 8555, erkek öğrenci sayıs1 4689) kız öğrencilerden oluşmasıdır (http://www.cumhuriyet.edu.tr/ogrenci/index.php?Dil=1\&d=410). Bu çalışmada da benzer oranlarda kadın ve erkeklerin temsil edilmesi yönünde bir tercih ortaya konmuştur. Yine katılımcıların çok büyük bir kısmı $(\% 80,7)$ sosyal bilimler alanında okuyan öğrencilerden oluşmaktadır. Bu da sosyal bilim alanında eğitim veren fakültelerin öğrenci sayısının diğerlerinden oldukça yüksek olmasından kaynaklanmaktadır. Sağlık ve sayısal bilimler alanında katılımcı sayısının az olması nedeniyle bu iki tabaka birleştirimiş, sağlık/sayısal bilimler ve sosyal bilimler alanı olarak iki kategori belirlenmesine karar verilmiştir. Katılımcıların 201'i (\%30,4) birinci 
sinıf, 181'i $(\% 27,3)$ ikinci sinıf, 174'ü $(\% 26,3)$ üçüncü sinıf, 106's1 $(\% 16,0)$ dördüncü sinıf öğrencisidir. 197 kişi $(\% 29,8)$ ailesinin aylık ortalama gelirinin 2000 TL'den az olduğunu söylerken, 298 kişi (\%45) 2001 ve 4000 TL arasında gelirleri olduğunu, 118 kişi $(\% 17,8) 4000$ ve üzeri gelire sahip olduğunu ifade etmiştir. Katılımcıların 426'sının $(\% 64,4)$ annesi ilkokul ve altında eğitim düzeyine sahipken, 210'nu (\%31,7)'si ortaöğretim mezunudur. Annesi üniversite mezunu olanların oranı ise \%3,9'dur. Katılımcıların 256'sının babası $(\% 38,7)$ ilkokul ve aşağısı, 316'sı $(\% 47,7)$ orta öğretim, 90’1 $(13,6)$ yüksek öğrenim düzeyine sahiptir. Katılımcıların yaş ortalaması \%21, 01 $(\mathrm{ss}=1,74)$ dir. $87(\% 13,1)$ katılımcı Doğu ve Güneydoğu illerinden, $362(\% 54,7)$ katılımcı İç Anadolu, $83(\% 12,5)$ katılımc1 Ege ve Marmara, $62(\% 9,4)$ katılımc1 Karadeniz, $68(\% 10,3)$ katılımc1 Akdeniz bölgesindeki illerden gelmektedir.

Tablo 1: Kat1lımc1lara Ait Demografik Bilgiler

\begin{tabular}{|c|c|c|c|}
\hline & Değişkenler & $\mathbf{N}$ & $\%$ \\
\hline \multirow{2}{*}{ Cinsiyet } & Kadın & 431 & 65,1 \\
\hline & Erkek & 231 & 34,9 \\
\hline \multirow{2}{*}{ Alan } & Sağlık ve sayısal bilimler & 128 & 19,3 \\
\hline & Sosyal bilimler & 534 & 80,7 \\
\hline \multirow{4}{*}{ Sinıf } & 1.Sinıf & 201 & 30,4 \\
\hline & 2.Sinıf & 181 & 27,3 \\
\hline & 3.Sinif & 174 & 26,3 \\
\hline & 4.Sinif & 106 & 16,0 \\
\hline \multirow{4}{*}{ Gelir } & 2000 TL ve altı & 197 & 29,8 \\
\hline & $2001 \mathrm{TL}-4000 \mathrm{TL}$ & 298 & 45,0 \\
\hline & $4001 \mathrm{TL}-6000 \mathrm{TL}$ & 118 & 17,8 \\
\hline & 6001 TL ve üzeri & 49 & 7,4 \\
\hline \multirow{5}{*}{$\begin{array}{c}\text { Gelinen } \\
\text { Bölge }\end{array}$} & Doğu ve Güneydoğu Anadolu & 87 & 13,1 \\
\hline & İç Anadolu & 362 & 54,7 \\
\hline & Ege ve Marmara & 83 & 12,5 \\
\hline & Karadeniz & 62 & 9,4 \\
\hline & Akdeniz & 68 & 10,3 \\
\hline \multirow{5}{*}{$\begin{array}{c}\text { Anne } \\
\text { Ĕgitim }\end{array}$} & Okuryazar değil & 94 & 14,2 \\
\hline & İlkokul & 332 & 50,2 \\
\hline & Ortaokul & 112 & 16,9 \\
\hline & Lise & 98 & 14,8 \\
\hline & Üniversite & 26 & 3,9 \\
\hline \multirow{5}{*}{$\begin{array}{c}\text { Baba } \\
\text { Ĕgitimi }\end{array}$} & Okuryazar değil & 30 & 4,6 \\
\hline & İlkokul & 226 & 34,1 \\
\hline & Ortaokul & 135 & 20,4 \\
\hline & Lise & 181 & 27,3 \\
\hline & Üniversite & 90 & 13,6 \\
\hline
\end{tabular}

\section{Katılımcıların Namus Adına Kadına Uygulanan Şiddete Yönelik Tutum Düzeyleri}

Katılımcıların NKUŞTÖ'nden aldıkları ortalama puan 25,18 'dir. Bu değer orta değerin oldukça altında bulunduğundan katılımcıların namus adına uygulanan şiddete karşı oldukları söylenebilir. NKUŞTÖ'nin maddelerine verilen cevaplar tek tek incelendiğinde en yüksek ortalamanın "Ne yapmış olursa olsun namus adına bir kadının şiddete maruz kalmaması gerektiğini düşünüyorum" (Ort: 2,27) maddesinden alındığı, bunu "Toplumsal düzenin korunması için toplumsal kurallara uymayan kadınların cezalandırılması gerektiğine inanıyorum." (Ort:2,04) ile "Akrabaların ailenin kadın namusu ile ilgili cezalar vermelerine kızıyorum." (Ort: 2,06) maddelerinin takip ettiği görülmektedir. Katılımcılar en düşük ortalamayı "Namusu kirlenmiş bir kadının ailenin şerefinin korunması adına öldürülmelidir." (Ort:1,25) maddesinden almışlardır.

\section{Turkish Studies - Social Sciences}

Volume 14 Issue 6, 2019 
Tablo 2: NKUŞTÖ’nün maddelerine İlişkin Betimsel İstatistik

\begin{tabular}{|c|c|c|c|c|c|}
\hline & $\mathrm{N}$ & Min. & Max. & $\chi$ & ss. \\
\hline $\begin{array}{l}\text { 1.Namusun korunması için gerekirse } \\
\text { kadına sözel şiddet uygulanabilir }\end{array}$ & 662 & 1 & 6 & 1,86 & 1,42 \\
\hline $\begin{array}{l}\text { 2. Namusu kirlenmiş bir kadın ailenin } \\
\text { şerefinin korunması adına öldürülmeli- } \\
\text { dir }\end{array}$ & 662 & 1 & 6 & 1,25 & 0,77 \\
\hline $\begin{array}{l}\text { 3.Namus cinayetlerinin toplumsal bir } \\
\text { terbiye aracı olarak işlevsel olabileceği- } \\
\text { ni düşünüyorum }\end{array}$ & 662 & 1 & 6 & 1,36 & 0,94 \\
\hline $\begin{array}{l}\text { 4. Namusu neden göstererek kadına } \\
\text { zarar verenleri kınıyorum }\end{array}$ & 662 & 1 & 6 & 1,84 & 1,50 \\
\hline $\begin{array}{l}\text { 5.Toplumsal kurallara aykırı davranan } \\
\text { kadınların toplum veya ailesi tarafindan } \\
\text { cezalandırılmasını haklı buluyorum }\end{array}$ & 662 & 1 & 6 & 2,04 & 1,45 \\
\hline $\begin{array}{l}\text { 6.Erkek akrabaların namus adına kadı- } \\
\text { na şiddet uygulaması beni rahatsız } \\
\text { eder. }\end{array}$ & 662 & 1 & 6 & 1,87 & 1,50 \\
\hline $\begin{array}{l}\text { 7. Namus adına işlenmiş̧ cinayetlerde } \\
\text { haklılık payı olduğuna inanıyorum }\end{array}$ & 662 & 1 & 6 & 1,69 & 1,22 \\
\hline $\begin{array}{l}\text { 8. Namusun temizlenmesi için kadının } \\
\text { öldürülmesine karşı değilim }\end{array}$ & 662 & 1 & 6 & 1,50 & 1,22 \\
\hline $\begin{array}{l}\text { 9. Ne yapmış olursa olsun namus adına } \\
\text { bir kadının şiddete maruz kalmaması } \\
\text { gerektiğini düşünüyorum }\end{array}$ & 662 & 1 & 6 & 2,27 & 1,85 \\
\hline $\begin{array}{l}\text { 10. Namus adı altında kadınlara şiddet } \\
\text { uygulanmasına karşıyım }\end{array}$ & 662 & 1 & 6 & 1,76 & 1,40 \\
\hline $\begin{array}{l}\text { 11.Akrabaların ailenin kadın namusu } \\
\text { ile ilgili cezalar vermelerine kızıyorum }\end{array}$ & 662 & 1 & 6 & 2,06 & 1,56 \\
\hline $\begin{array}{l}\text { 12.Namus uğruna kadınların öldürül- } \\
\text { mesine karşııım }\end{array}$ & 662 & 1 & 6 & 1,62 & 1,32 \\
\hline $\begin{array}{l}\text { 13. Başına ne gelmiş olursa olsun } \\
\text { namusunu koruyamamış olan kadın- } \\
\text { ların kınanması gerektiğini } \\
\text { düşünüyorum }\end{array}$ & 662 & 1 & 6 & 1,72 & 1,36 \\
\hline $\begin{array}{l}\text { 14.Toplumsal düzenin korunması için } \\
\text { toplumsal kurallara uymayan kadınların } \\
\text { cezalandırılması gerektiğine } \\
\text { inanıyorum }\end{array}$ & 662 & 1 & 6 & 2,25 & 1,64 \\
\hline NKUŞTÖ & 662 & 14 & 59 & 25,18 & 11,10 \\
\hline
\end{tabular}

\section{Tutum}

Sosyo-demografik Özellikler ve Namus Adına Kadına Uygulanan Şiddete Yönelik

Namus Adına Kadına Uygulanan Şiddete Yönelik Tutumun ikili gruplar (cinsiyet ve eğitim görülen alanlar) açısından farklılaşıp farklılaşmadığı bağımsız örneklem t testi ile analiz edilmiştir. Analiz sonucu, kadın ve erkekler arasında namus adına kadına uygulanan şiddete yönelik tutumun farklılaştı̆̆ını göstermektedir $\left(\mathrm{t}_{(660)}=-10,547 ; \mathrm{p}<0,05\right)$. Ölçekten alınan ortalamalar dikkate alındığında erkeklerin (Ort: 30,93) kadınlardan (Ort: 22,09) daha yüksek puan aldığı anlaşılmaktadır. Dolayısıyla erkeklerin namus adına işlenen şiddeti daha çok destekledikleri söylenebilir.

Benzer şekilde namus adına kadına uygulanan şiddete yönelik tutumun okunulan alan açısından farklılaştığı da görülmektedir $\left(\mathrm{t}_{(659)}=1,976 ; \mathrm{p}<0.05\right)$. Ölçek ortalamaları, sağlık ve sayısal bilimler alanında eğitim görenlerin (Ort: 26,92) sosyal bilimler alanında eğitim alan öğrencilerden (Ort: 24,76) daha yüksek olduğunu göstermektedir. Bu durum sosyal bilimler alanında eğitim

\section{Turkish Studies - Social Sciences}

Volume 14 Issue 6, 2019 
görenlerin namus adına kadınlara uygulanan şiddeti diğer alanlarda okuyanlara kıyasla daha az meşrulaştırdıklarını göstermektedir.

Namus adına kadına uygulanan şiddete yönelik tutumunun ikiden daha fazla gruplar açısından ( sınıf düzeyi, gelir, üniversiteye gelmeden önce yaşadığı bölge ile anne baba eğitim düzeyi) farklılaşıp farklılaşmadığı tek yönlü ANOVA ile analiz edilmiştir. Elde edilen bulgulara göre, namus adına kadına uygulanan şiddete yönelik tutum sınıflar arasında farklılaşmaktadır $\left(\mathrm{F}_{(3,658)}=7,936 ; \mathrm{p}<0,00\right)$. Farklılı̆gın hangi gruplar arasında olduğu TUKEY testiyle belirlenmiş olup, 1. sınıf öğrencilerinin 3. ve 4. sınıf; 2. sınıf öğrencilerinin ise 3. sınıf öğrencileriyle tutumlarının farklılaştığı saptanmıştır. 1. sinıf öğrencilerinin (Ort: 27,58) 3. sınıf (Ort:22,32) ve 4. Sınıf (Ort:23,99) öğrencilerine kiyasla; 2. sınıf ögrencilerinin (Ort: 25,97) ise 3. Sınıf (Ort: 22,32) öğrencilerine kıyasla namus adına kadına yönelik şiddete olumlu baktığı görülmektedir.

Namus adına kadına uygulanan şiddete yönelik tutum öğrencilerin ailelerinin gelir düzeyine göre farklılaşmamaktadır $\left(\mathrm{F}_{(3,658)}=2,351 ; \mathrm{p}>0,05\right)$. Yine namus adına kadına uygulanan şiddet gelinen bölgeye göre de farklılaşmamıştır $\left(\mathrm{F}_{(4,657)}=0,771 ; \mathrm{p}>0,05\right)$. Her ne kadar ölçekten alınan ortalamalara bakıldığında Doğu ve Güneydoğu Anadolu Bölgesinden gelen öğrencilerin puan ortalamalarının diğer bölgelere göre yüksek olduğu dikkat çekse de bu farklılı̆̆ın istatistiksel olarak anlamlı olmadığı görülmektedir.

Gençlerin anne eğitim düzeyine göre namus adına kadına uygulanan şiddete yönelik tutumlarının gruplar arasında farklılaştığı ortaya konulmuş olup $\left(\mathrm{F}_{(4,657)}=2,511 ; \mathrm{p}<0,05\right)$, yapılan TUKEY testine göre farklılı̆̆ın annesi okur-yazar olan grup ile diğer gruplar arasında olduğu saptanmıştır. Annesi okur-yazar olanlar namus adına kadına yönelik şiddeti diğer gruplardan daha çok desteklemektedir. Baba eğitim düzeyine göre ise, gruplar arasında bir farklılık saptanmamıştır $\left(\mathrm{F}_{(4,657)}=1,155 ; \mathrm{p}>0,05\right)$. 
Tablo 3: Bağımsız Örneklem t Testi ile Tek Yönlü Anova Sonuçları

\begin{tabular}{|c|c|c|c|c|c|c|c|}
\hline Cinsiyet & $\begin{array}{l}\text { Kadın } \\
\text { Erkek }\end{array}$ & $\begin{array}{c}\mathbf{N} \\
431 \\
231 \\
\end{array}$ & $\begin{array}{c}\text { Ort. } \\
22,09 \\
30,93 \\
\end{array}$ & $\begin{array}{c}\text { SS. } \\
9,34 \\
11,82 \\
\end{array}$ & $\begin{array}{c}\mathbf{T} \\
-10,547\end{array}$ & $\begin{array}{l}\text { Sd. } \\
660\end{array}$ & $\begin{array}{c}p \\
0,00\end{array}$ \\
\hline Alan & $\begin{array}{l}\text { Sağlık-Fen bilimleri } \\
\text { Sosyal bilimler }\end{array}$ & $\begin{array}{l}128 \\
534 \\
\end{array}$ & $\begin{array}{l}26,92 \\
24,76 \\
\end{array}$ & $\begin{array}{l}11,78 \\
10,90 \\
\end{array}$ & 1,976 & 660 & 0,04 \\
\hline & & $\mathbf{N}$ & Ort. & SS. & $\mathbf{F}$ & Sd. & $\mathbf{p}$ \\
\hline Sinıf & $\begin{array}{l}\text { 1.Sinif } \\
\text { 2.Sinif } \\
\text { 3.Sinif } \\
\text { 4.Sinif } \\
\end{array}$ & $\begin{array}{l}201 \\
181 \\
174 \\
106 \\
\end{array}$ & $\begin{array}{l}27,58 \\
25,97 \\
22,32 \\
23,99 \\
\end{array}$ & $\begin{array}{l}10,78 \\
11,36 \\
10,86 \\
10,56 \\
\end{array}$ & 7,936 & $\begin{array}{c}3 \\
658\end{array}$ & $\mathbf{0 , 0 0}$ \\
\hline Gelir & $\begin{array}{l}2000 \mathrm{TL} \text { ve alt1 } \\
2001 \mathrm{TL}-4000 \mathrm{TL} \\
4001 \mathrm{TL}-6000 \mathrm{TL} \\
6001 \mathrm{TL} \text { ve üzeri } \\
\end{array}$ & $\begin{array}{c}197 \\
298 \\
118 \\
49 \\
\end{array}$ & $\begin{array}{l}28,87 \\
25,72 \\
24,45 \\
24,02 \\
\end{array}$ & $\begin{array}{l}11,34 \\
10,68 \\
11,29 \\
10,68 \\
\end{array}$ & 2,351 & $\begin{array}{c}3 \\
658\end{array}$ & 0,07 \\
\hline Bölge & $\begin{array}{l}\text { Doğu ve Güney Doğu } \\
\text { Anadolu } \\
\text { İç Anadolu } \\
\text { Ege ve Marmara } \\
\text { Karadeniz } \\
\text { Akdeniz } \\
\end{array}$ & $\begin{array}{c}87 \\
362 \\
83 \\
62 \\
68 \\
\end{array}$ & $\begin{array}{l}27,36 \\
24,83 \\
25,33 \\
24,82 \\
25,05 \\
\end{array}$ & $\begin{array}{l}11,24 \\
10,29 \\
10,35 \\
11,92 \\
\end{array}$ & 0,771 & $\begin{array}{c}4 \\
657\end{array}$ & 0,54 \\
\hline $\begin{array}{l}\text { Anne } \\
\text { eğitim } \\
\text { düzeyi }\end{array}$ & $\begin{array}{l}\text { Okur yazar değil } \\
\text { İlkokul } \\
\text { Ortaokul } \\
\text { Lise } \\
\text { Üniversite }\end{array}$ & $\begin{array}{c}94 \\
332 \\
112 \\
98 \\
26 \\
\end{array}$ & $\begin{array}{l}28,30 \\
24,84 \\
24,08 \\
24,24 \\
24,10 \\
\end{array}$ & $\begin{array}{l}12,56 \\
10,44 \\
11,29 \\
11,32 \\
10,64\end{array}$ & 2,511 & $\begin{array}{c}4 \\
657\end{array}$ & 0,04 \\
\hline $\begin{array}{l}\text { Baba } \\
\text { eğitim } \\
\text { düzeyi }\end{array}$ & $\begin{array}{l}\text { Okur yazar değil } \\
\text { İlkokul } \\
\text { Ortaokul } \\
\text { Lise } \\
\text { Üniversite }\end{array}$ & $\begin{array}{c}30 \\
226 \\
135 \\
181 \\
90\end{array}$ & $\begin{array}{l}29,23 \\
24,61 \\
25,18 \\
25,32 \\
25,18\end{array}$ & $\begin{array}{l}12,30 \\
10,45 \\
11,96 \\
10,94 \\
11,19\end{array}$ & 1,155 & $\begin{array}{c}4 \\
657\end{array}$ & 0,33 \\
\hline
\end{tabular}

\section{Tartışma}

$\mathrm{Bu}$ araştırmada üniversite öğrencilerinin namus adına kadına uygulanan şiddete yönelik tutumları bazı sosyo-demografik değişkenler açısından incelenmiş ve aşağıdaki bulgulara ulaşılmıştır:

İlk olarak bu araştırmada öğrencilerin namus bahanesi ile kadınlara uygulanan şiddeti desteklemediği saptanmıştır. Bunun bir göstergesi olabilecek şekilde öğrenciler, ölçek maddeleri içerisinde en yüksek ortalamayı "Ne yapmış olursa olsun namus adına bir kadının şiddete maruz kalmaması gerektiğini düşünüyorum" maddesinden almışlardır. Çalışmada elde edilen bulgu, Işık ve Sakallı-Uğurlu (2009) ile Berrin Bulut ve Yıldırım (2018)'ın çalışmasındaki bulgularla aynı doğrultudadır. Her iki çalışmada üniversite öğrencileriyle yapılmış olup katılımcıların namus adına kadına uygulanan şiddete karşı oldukları ortaya konmuştur. Işık ve Sakallı-Uğurlu (2009) bu sonucu öğrencilerin sosyal olarak kabul edilebilecek cevaplar verme eğilimiyle açıklamaktadır. Bu durum sosyal psikolojide" sosyal istenirlik" olarak adlandırılmakta, "bireyin herhangi bir ölçme aracının maddelerini yanttlarken, kendisiyle ilgili gerçekçi bilgiler vermek yerine kendini sosyal ve normatif anlamda olumlu biçimde sunması eğilimi”" (Ellingson, Smith ve Sackett, 2001: 122) olarak tanımlanmaktadır. Anketi dolduran bireylerden herhangi bir ismin istenmediği araştırmalarda dahi katılımcılar olumlu bir sosyal imaj sunma eğiliminde olabilmektedir (Akın, 2010). Her ne kadar bu varsayımın doğruluk payı olsa da, burada eğitimin etkisinin de gözden kaçırılmaması gerektiği düşünülmektedir. Eğitim düzeyinin yükselmesiyle birlikte toplumun cinsiyet rollerini daha uygar şekilde algılaması sağlanabilmektedir (Berrin Bulut ve Yıldırım, 2018; Güneri Er ve Şen, 2018). 
Bunun sonucu olarak katılımcıların namus algıları toplumun genelinden farklılaşmış olabilir. Nitekim eğitim ile birlikte hem kadın hem de erkekler grubunda toplumsal cinsiyet eşitliğinin daha çok onaylandığı ve kadına ilişkin eşitlikçi namus anlayışının belirginleştiği birçok çalışmada ortaya konmuştur (Aktaş ve Külcü, 2019; Güneri Er ve Şen, 2018; Gürsoy ve Arslan-Özkan, 2014). Yine araştırmalar eğitim düzeyi yükseldikçe kadına yönelik şiddete tepkinin de yükseldiğini göstermektedir (Bulut, 2016; Kabasakal ve Girli, 2012; Sakallı, 2001; Sakallı ve Ulu, 2003). Özellikle kadınların kendilerine yönelik şiddete tepki gösterme oranı eğitim düzeyiyle paralel olarak artmaktadır (Kabasakal ve Girli, 2012; Sakallı ve Ulu, 2003).

İkinci olarak bu çalışmada erkeklerin namus adına kadına yönelik uygulanan şiddeti kadınlara kıyasla daha fazla onayladıkları saptanmıştır. Bu durum hem tek tek ölçek maddeleri için hem de ölçeğin geneli için geçerlidir. Örneğin katılımcıların "Toplumsal düzenin korunması için toplumsal kurallara uymayan kadınların cezalandırılması gerektiğine inanıyorum" maddesinden yüksek puan almalarında erkeklerin etkisi dikkat çekicidir (Erkekler için ort: 2,88; kadınlar için ort:1,95). Benzer şekilde ölçeğin geneli düşünüldügünde erkekler namus adına kadına yönelik uygulanan şiddeti kadınlara kıyasla daha fazla onaylamaktadırlar. Literatürde yapılan çalışmalarda cinsiyetin genelde kadına yönelik şiddet (Bkz. Sakallı, 2001; Sakallı-Uğurlu ve Ulu, 2003) özelde namus adına kadına yönelik şiddete bakışı etkileyen önemli değişkenlerden birisi olduğu; erkeklerin namus adına kadına yönelik şiddete ilişkin puan ortalamalarının kadınlardan daha yüksek olduğu saptanmıştır (Bkz. Berrin Bulut ve Yıldırım, 2018; Çalık, 2017; Demirel vd., 2019; Işık, 2008; Kaya ve Turan, 2018; SakallıUğurlu ve Ulu, 2003). Literatür kısmında değinildiği üzere erkeklerin namus adına kadına yönelik şiddeti daha çok desteklemeleri ataerkil sosyalleşme sürecinin bir sonucudur (Bkz. Sakallı ve Akbaş, 2013). Bu tür toplumsal yapılarda erkekler namusu "cinsel saflık" olarak algılamakta ve çevresindeki kadınların namusunu (özellikle cinsel saflı̆̆ını) korumakla görevli oldukları yönünde sosyalleştirilmektedir (Tahincioğlu, 2011). Nitekim Sakallı ve Glick (2003) ile Gürsoy ve ArslanÖzkan (2014) Ankara'da üniversite öğrencileriyle yaptıkları çalışmada erkeklerin bu geleneksel yargılardan etkilendiklerini ortaya koymuşlar, erkek öğrencilerin kadına ilişkin namus algısına yönelik tutumlarının kız öğrencilerin tutumlarına göre daha olumsuz olduğunu, özellikle evlilik öncesi kadının cinsellik yaşamasına karşı olduklarını saptamışlardır. Yine Kodan-Çetinkaya (2013) erkek öğrencilerin toplumsal cinsiyet rollerine ilişkin düşüncelerinin daha geleneksel olduğunu saptamıştır. $\mathrm{Bu}$ düşünceler erkeklerin namusu korumak adına kadınlara uygulanan şiddeti mazur görmelerine neden olabilmektedir (Işı1k, 2008; Sakallı ve Akbaş, 2013).

Üçüncü olarak bu araştırmada sağlık ve sayısal bilimler alanında öğrenim gören öğrencilerin sosyal alanda öğrenim gören öğrencilere kıyasla namus adına kadına uygulanan şiddete daha olumlu yaklaştıkları ortaya konmuştur. Bu durumun muhtemelen sosyal bilimler alanında (sosyoloji, psikoloji, sosyal hizmet vb) toplumsal cinsiyet eşitliği, aile veya kadına yönelik şiddetle ilgili derslerin yer almasından kaynaklanmış olabileceği düşünülmektedir. Sosyoloji/antropoloji gibi bölümlerde toplumun kültürel yapısının tartışıldığı derslerin bulunmasının öğrencilerin namus anlayışlarını değiştirmiş olma ihtimali göz ardi edilmemelidir (Çağlayan, 2019). Nitekim Gürsoy (2009) çalışmasında sosyal bilim alanındaki öğrencilerin namus anlayışının daha eşitlikçi olduğunu ortaya koymuştur. Bunun yanında bu çalışma kapsamında, kadın öğrenci sayısının sosyal bilimler alanında daha fazla olmasının böyle bir farkın oluşmasında etkili olabileceği düşünülmektedir. Dolayısıyla alanlar arasındaki farklılığın gerçekte neden kaynaklandığının anlaşılabilmesi için yeni çalışmalara ihtiyaç duyulduğu açıktır.

Dördüncü olarak bu araştırmada sınıf düzeyi yükseldikçe namus bahanesiyle kadına uygulanan şiddeti destekleme düzeyinin düştügü saptanmıştır. Bulgu, üniversitede geçen süre arttıkça toplumsal norm ve değerlere yönelik eleştirel bakışın ve sorgulamanın namus konusunda da sorgulamayı beraberinde getirdiğini, eşitlikçi toplumsal cinsiyet rolünün daha çok benimsendiğini göstermektedir. Nitekim Dadashzadeh (2016) tarafından yapılan çalışmada kadına ilişkin namus anlayışı tutum ölçeğinin alt boyutlarından eşitlikçi namus anlayışı puan ortalamalarının 1. ve 4. sınıflar

\section{Turkish Studies - Social Sciences}

Volume 14 Issue 6, 2019 
arasında farklılaştığının saptanması, dördüncü sınıfların ortanca puanının birinci sınıflardan daha yüksek olduğunun ortaya konması bu iddianın doğruluğunu güçlendirmektedir. Benzer şekilde Demirel ve arkadaşları (2019) 4. sınıf öğrencilerinin namusla ilişkili daha eşitlikçi tutuma sahip olduklarını saptamıştır. Bunun yanında bu çalışma kapsamında üst sınıflarda okuyan kadın öğrenci sayısının erkek öğrenci sayısından fazla olmasının da böyle bir sonucu doğurmuş olabileceği düşünülmektedir.

Beşinci olarak bu çalışmada öğrencilerin gelir düzeyine göre namus adına kadınlara uygulanan şiddete yönelik tutumlarının farklılaşmadığı saptanmıştır. Her ne kadar ekonomik statü açısından gruplar arasında farklılık çıkmış olsa da bu farklılık istatistiksel bir anlam ifade etmemektedir. Işık (2008), gelir düzeyi ile namus adına kadına uygulanan şiddete yönelik tutum arasında negatif ilişki olduğunu, gelir düzeyi düştükçe namus için kadınlara uygulanan şiddetin daha çok onaylandığını saptamıştır. Bu çalışmada ekonomik statü açısından gruplar arasında farklılık çıkmaması muhtemelen gelirle ilgili sorunun yapısından kaynaklanmaktadır. Çalışmada katılımcılardan gelir düzeylerini alt, orta ve üst gelir seviyesinden birisini işaretleyerek cevaplandırmaları istenmiştir. Katılımcıların bu soruya sübjektif cevap verme ihtimali söz konusudur. Çünkü bireylerin algılarını kişisel özellikleri, geçmiş yaşamlarındaki tecrübeleri, yaşadıkları çevre ve sahip oldukları değerler etkileyebilir. Bu çerçevede aynı gelire sahip olsalar bile kişilerfarklı değerlendirmede bulunabilirler (Öztürk, 2015).

Altıncı olarak bu araştırmada hipotezin aksine öğrencilerin geldikleri bölgeye göre namus adına kadınlara uygulanan şiddete yönelik tutumlarının farklılaşmadığı saptanmıştır. Oysa feodal yapının gücünü koruduğu bölgelerde geleneksel namus anlayışının hakim olduğu ve namus adına cinayetlere kadar giden şiddet eylemlerinin yoğun olduğu bilinmektedir (Bilgili ve Vural, 2011). Bu toplumsal kabulle büyüyenlerin namus adına kadına yönelik şiddeti olumlamaları ihtimaldir. Ancak bu çalışmada, bölgeler arasında farklılaşmanın olmamasının muhtemelen nedeni öğrencilerin büyük çoğunluğunun kent merkezlerinden gelmeleridir. Nitekim örneklemin yaklaşı \% $\% 62$ 'si (410 kişi) kent merkezinde doğup büyüdüğünü söylerken, \%38'i (252) ilçe, kasaba ve köylerden geldiklerini beyan etmişlerdir. Kentler, modern değerlerin kabul gördüğü, modern yaşamın hâkim olduğu alanlardır. Kentlerde; geleneklerde, örf ve adetlerde meydana gelen değişimle birlikte kadın erkek arasındaki cinsiyet eşitsizliğinin daha az yaşanması, kadınların eğitime devam etme durumu, iş yaşamı ve sosyal hayata daha fazla katılımı gibi etkenler katılımcıların namus algılarını değiştirmiş olabilir. Bunu destekleyecek şekilde Çağlayan (2019) ile Güneri Er ve Şen (2018) kentsel alanlarda yaşayanların namus anlayışı tutumlarının daha eşitlikçi olduğunu saptamışlardır.

Son olarak bu araştırmada anne eğitim düzeyi yükseldikçe öğrencilerin namus adına kadınlara uygulanan şiddeti onaylama düzeylerinin düştüğü, baba eğitim düzeyinde ise böyle bir farklılaşmanın olmadığı saptanmıştır. Bu durum araştırmanın giriş bölümünde de ifade edildiği üzere çocukların eğitiminde annenin rolünü ortaya koymaktadır. Çocukların toplumsal değerleri öğrenmelerinde ve içselleştirmelerinde aile önemli bir yere sahiptir. $\mathrm{Bu}$ süreçte anne-babanın eğitim düzeyi ailenin yapısını, iletişim biçimini, aile içerisindeki tutumlarını vedavranışlarını etkilemekte, çocuk ta içinde bulunduğu aile ortamına göre yetişmektedir (Çağlayan, 2019). Türk aile yapisında özellikle anne çocuk eğitiminde birincil roldedir (Özensel, 2004). Dolayısıyla annenin eğitim düzeyi çocuğa hangi toplumsal rolleri ve değerleri benimseteceğini daha çok belirlemektedir. Bu konuda yapılan çalışmalarda eğitim düzeyi yüksek annelerin toplumun genelinden farklı olarak namus algılarının daha eşitlikçi, kadına şiddet konusunda daha duyarlı, toplumsal cinsiyet rollerine yönelik daha eleştirel olduğu ortaya konmuştur (Bkz. Cirhinoğlu ve Şenel, 2017; Çağlayan, 2019; Güneri Er ve Şen, 2018; Gürsoy, 2009; Gürsoy ve Arslan-Özkan, 2014; Kodan-Çetinkaya, 2013; Zeyneloğlu, Kısa ve Yılmaz, 2013). Buradan yola çıkarak daha eşitlikçi namus anlayışına sahip bir anlayışla yetiştirilen gençlerin namus adına işlenen şiddeti desteklemeyeceği olasıdır. Araştırmada baba eğitim düzeyine göre katılımcıların namus adına işlenen şiddete yönelik tutumlarının farklılaşmaması babanın çocuk yetiştirme üzerindeki rolünün anneye göre daha geride olması ile açıklanabilir. 


\section{Sonuç ve Öneriler}

$\mathrm{Bu}$ araştırmada dikkat çekici bir bulgu öğrencilerin namus adına kadına uygulanan şiddete onay vermediğidir. $\mathrm{Bu}$ sonuç doğrultusunda üniversite öğrencilerinin namus ve şiddetle ilişkili farkındalıklarının ve bilinç düzeylerinin yüksek olduğu söylenebilir. Buna karşın erkeklerin namus adına kadına uygulanan şiddeti daha fazla onaylamaları ilginçtir. Bunu engelleyebilmek adına kadına yönelik şiddet, namus anlayışı ve toplumsal cinsiyet gibi konuları içeren derslerin tüm bölümlere eklenmesinin gerekli olduğu söylenebilir. Hatta söz konusu derslerin lise düzeyinden itibaren başlatılmasının ataerkil toplumsal yapının bir ürünü olan namus adına kadına yönelik şiddeti önlemede etkili olabileceği düşünülmektedir. Bunun yanında, bu konularla ilgili hem lise hem de üniversite düzeyinde konferans, seminer gibi etkinlikler düzenlenmekte şiddetle mücadelede olumlu sonuçlar verecektir (Demirel vd., 2019).

Çalışmada ayrıca anne eğitim düzeyinin öğrencilerin namus adına kadına uygulanan şiddete yönelik tutumlarını etkilediği de saptanmıştır. Bu sonuç, katı toplumsal norm ve değerlerin değiştirilebilmesinde kadınların eğitimlerinin ne kadar önemli olduğunu bir kere daha göstermektedir. Geleceğin anne adayları olacak kadınların eğitim düzeylerinin yükselmesi sayesinde ülkemizdeki geleneksel cinsiyetçi rolleri ile katı namus algısı tutumları değiştirilebilir, namus adına kadına karşı uygulanan şiddet suçları ve cinayetler azaltılabilir.

Namus ve namus adına kadına uygulanan şiddetle ilişkili tutumu ölçmek amacıyla yapılan çalışmaların genellikle üniversite öğrencileriyle yapıldığı görülmektedir. Bu çalışma da da örneklem grubu yükseköğrenim öğrencilerinden oluşmaktadır. Ülkemizde konu ile ilgili farklı örneklem grupları ve farklı değişkenlerle yapılacak çalışmaların literatüre katkı sağlayacağı böylece toplumsal tutumu daha net ortaya koyacağı düşünülmektedir (Demirel vd.,2019).

$\mathrm{Bu}$ araştırma, makro sosyo-demografik veriler temelinde namus adına kadına yönelik şiddete yönelik tutumları incelemiştir. Söz konusu olguya yönelik daha kapsamlı bilgi edinebilmek için makro değişkenlerle birlikte mikro bağlamlara odaklanılması gerekliliği de vardır.

Son olarak bu araştırmada kadın öğrenci sayısı erkek öğrenci sayısının iki katıdır. Bu durum elde edilen bulguların yorumlanmasında dikkatli olmayı gerektirmektedir. Bundan sonra yapılacak çalışmalarda örneklem dağılımının benzer oranlarda yapılmasının sonuçların daha sağlıklı yorumlanabilmesi açısından önem taşıdığı düşünülmektedir. .

\section{KAYNAKÇA}

Akbaba, Z. B. (2008). Töre, Namus ve Töre Saikiyle Kasten Öldürme. TBB Dergisi, 75, 333-352

Aksoy, A. ve Yılmaz-Vefikuluçay, D. (2019). Bir İnsan Hakları İhlali: Namus Cinayetleri. Researcher: Social Science Studies, 7(1): 01-19.

Akın, A. (2010). İki Boyutlu Sosyal İstenirlik Ölçeğinin Geliştirilmesi ve Psikometrik Özelliklerinin Araştırılması. Gazi Eğitim Fakültesi Dergisi, 30(3):771-784.

Aktaş, D. ve Külcü, D. P. ( 2019). Hemşirelik Öğrencilerinin Toplumsal Cinsiyet Rolleri ile Kadına İlişkin Namus Algıları Arasındaki İlişki, Türkiye Klinikleri. DOI: 10.5336/mdethic.201966250

Arıcı, F. (2011). Üniversite Öğrencilerinde Toplumsal Cinsiyet Rollerine İlişkin Algılar Ve Psikolojik L̇yi Oluş (Yayınlanmamış Yüksek Lisans Tezi). Hacettepe Üniversitesi Sosyal Bilimler Enstitüsü. Ankara

Berber, N. (2016). Kadına Yönelik Şiddet. Feryal Saygılıgil (Haz.), Toplumsal Cinsiyet Tartışmaları içinde (ss.249-270). Ankara: Dipnot.

\section{Turkish Studies - Social Sciences}

Volume 14 Issue 6, 2019 
Bilgili, N. ve Vural, G. (2011). Kadına Yönelik Şiddetin En Ağır Biçimi: Namus Cinayetleri. Anadolu Hemşirelik ve Sağllk Bilimleri Dergisi, 14(1):66-72).

Bourdıu, P. (2016). Eril Tahakküm. Çev. Bediz Yılmaz, İstanbul: Bağlam Yayınları.

Bulut, M.B. (2016). Kadına Yönelik Şiddet İle Dini Dünya Görüşleri Arasındaki İlişkinin İncelenmesi. Bilimname, XXXII(3): 83- 108.

Bulut, M. B. Ve Yıldırım, G. A. (2018). Namus Adına Kadına Uygulanan Şiddet Ve Değer Yönelimleri Arasındaki İlişkiler. Turkish Studies, 13/26: 217-234 DOI: 10.7827/TurkishStudies.14294

Cirhinlioğlu, F. G. ve Şenel, A. F. (2017). Kadına İlişkin Namus Anlayışı, Değerler ve Cinsiyet Rolleri Arasındaki İlişki. The Journal of Academic Social Science Studies, 7(60), 311-324.

Çağlayan, M. Ç. (2019). Erkek Üniversite Öğrencilerin Kadın ve Namus Algısı (Yayımlanmamış Yüksek Lisans Tezi). 19 Mayıs Üniversitesi Sağlık Bilimleri Ensititüsü, Samsum.

Çalık, K. Y. (2017). Attitudes of Turkish Academics Regarding Violence Against Women in the Name of Honor. Journal of Interpersonal Violence, 33(20): 3232-3254.

Dadashzadeh, R. (2016). Üniversite Öğrencilerinin Kadına İlişkin 'Namus' Algısı (Yayımlanmamış Doktora Tezi). On dokuz Mayıs Üniversitesi, Eğitim Bilimleri Enstitüsü, Samsun.

Demirel, G., Kaya, N., Ertekin, P. Ş., Değerli, B. ve Gökmen, E. (2019). University Students' Attitudes Toward Sexism, Honor, and Violence Against Women. Journal of Health Science and Profession, 6(3): 479-90.

Devers, L. ve Bacon, S. (2010). Interpreting Honor Crimes: The Institutional Disregard Towards Female Victims of Family Violence in the Middle East. International Journal of Criminology and Sociological Theory, 3: 359- 371.

Dietrich, D. M. and Schuett, J. M. (2013). Culture of Honor and Attitudes Toward Intimate Partner Violencein Latinos. Sage Open, 3: 1-11.

Dinç, H. ve Hotun Şahin, N. (2009). Bir Kadın Sağlığı Sorunu: Töre ve Namus Cinayetleri, İ.Ü.F.N. Hemşirelik Dergisi,17(2): 123-132.

Doğan, R. (2016), Namus, Töre ve Eril Şiddet. Ankara: Ütopya.

Dökmen, Y. Z. (2010), Toplumsal Cinsiyet, Remzi Kitapevi, İstanbul

Ellingson, J. E., Smith, D. B. ve Sackett, P. R. (2001). Investigating the Influence of Social Desirability on Personality Factor Structure. Journal of Applied Psychology, 86: 122-133.

Engels F. (1990), Ailenin, Özel Mülkiyetin ve Devletin Kökeni, Çev: Kenan Somer, Sol Yayınları, Ankara

Grewal, I. (2013). Outsourcing Patriarchy. International Feminist Journal of Politics, 15(1): 119. doi:10.1080/14616742.2012.755352

Grzyb, M. A. (2016). An explanation of Honour-Related Killings of Women in Europe Through Bourdieu's Concept of Symbolic Violence and Masculine Domination. Current Sociology, 64: $1036-1053$

Güneri Er, S. ve Şen S. (2018). Üniversite Öğrencilerinin Kadına İlişkin Namus Anlayışı Tutumları, Sürekli Tip Eğitimi Dergisi, 27(4): 258-266.

Gürsoy, E. (2009). Üniversite Son Sınıf Öğrencilerinin Kadına İlişkin "Namus" Anlayışı İle İlgili Tutumları (Ankara Örneklemi) (Yayımlanmamış Doktora Tezi). Marmara Üniversitesi Sağl1k Bilimleri Enstitüsü. İstanbul. 
Gürsoy, E. ve Arslan-Özkan H. (2014). Türkiye'de Üniversite Öğrencilerinin Kadına İlişskin "Namus" Algis1. Psikiyatri Hemşireliği Dergisi, 5(3):149-159.

Işık, R. (2008). The Predictors of Understanding of Honor and Attitudes Toward Honor Related Violence: Ambivalent Sexism and System Justification (Yayınlanmamıs yüksek lisans tezi). Orta Doğu Teknik Üniversitesi Sosyal Bilimler Enstitüsü. Ankara.

Işık, R. ve Sakallı-Uğurlu, N. (2009). Namusa ve Namus Adına Kadına Uygulanan Şiddete İlişkin Tutumlar Ölçeklerinin Öğrenci Örneklemiyle Geliştirilmesi. Türk Psikoloji Yazıları, 12(24): $16-24$.

Kabasakal, Z. ve Girli, A. (2012). Üniversite Öğrencilerinin Kadına Yönelik Şiddet Hakkındaki Görüşlerinin, Deneyimlerinin Bazı Değişkenler Ve Yaşam Doyumu İle İlişkisi (DEÜ Buca Eğitim Fakültesi Örneği). Dokuz Eylül Üniversitesi, Sos. Bil. Ens. Dergisi, 14(2):105-123.

Kardam, F. (2005). Türkiye'deki Namus Cinayetlerinin Dinamikleri: Eylem Programı İçin Öneriler Sonuç Raporu. Nüfus Bilim Derneği-Birleşmiş Milletler Nüfus Fonu, Birleşmiş Milletler Kalkınma Programı, Ankara.

Kaya, N. ve Turan, N. (2018). Attitudes Toward Honor and Violence Against Women for Honor in the Context of the Concept of Privacy: A Study of Students in the Faculty of Health Sciences. Istanbul University Journal of Communication Sciences, 54: 65-84.

Khan, R. (2018). Attitudes Towards 'Honor' Violence and Killings in Collectivist Cultures: Gender Differences in Middle Eastern, North African, South Asian (MENASA) and Turkish Populations. J. L. Ireland, P. Birch ve C. A. Ireland (ed.), The Routledge International Handbook of Human AggressionCurrent Issues and Perspectivesiçinde (ss. 216-226). London: Routledge, https://doi.org/10.4324/9781315618777

Kodan Çetinkaya, S. (2013). Üniversite Öğrencilerinin Şiddet Eğilimlerinin ve Toplumsal Cinsiyet Rollerine İlişkin Tutumlarının İncelenmesi. Nesne, 1(2): 21-43.

Mies M, (2012), Ataerki ve Birikim, Çev: Yıldız Temurtürkan, Dipnot Yayınları, Ankara.

Moritz, M. (2008). A Critical Examination of Honour Cultures and Herding Societies in Africa. African Studies Review, 51 (2): 99-117.

Özensel, E. (2004). Türk Toplumunda Çocuğun Yetiştirilmesinde Annenin Rolü: Konya İli Örneği. Değerler Ĕgitimi Dergisi, 2(6): 77-96.

Öztürk, M. ve Demirdağ, M. A. (2013). Namusunu Kanla Temizleyenler: Mardin Cezaevi’nde Namus Davası Nedeniyle Yatan Mahkûmlar Üzerine Bir Araştırma. Sosyal Politika Çalışmaları, 7(30), 117-135.

Öztürk, M. (2015). Suç Korkusu ve Yaşam Doyumu Arasındaki İlişki: Mersin İli Örneği (Yayımlanmamış Doktora Tezi). Cumhuriyet Üniversitesi Sosyal Bilimler Enstitüsü, Sivas.

Pınar, G., Taşkın, L. ve Eroğlu K. (2008). Başkent Üniversitesi Öğrenci Yurdunda Kalan Gençlerin Toplumsal Cinsiyet Rol Kalıplarına İlişkin Tutumları. Hacettepe Üniversitesi Săgllk Bilimleri Fakültesi Hemşirelik Dergisi, 47-57.

Sakall, N. (2001). Beliefs About Wife Beating Among Turkish College Students: The Effects of Patriarchy, Sexism, and Sex Differences. Sex Roles, 44 (9/10): 1-12.

Sakalli-Uğurlu, N ve Glick, P. (2003). Ambivalent Sexism and Attitudes Toward Women who Engage in Premarital Sex in Turkey. The Journal of Sex Research, 40: 296-302.

Sakallı-Uğurlu, N. ve Ulu, S. (2003). Evlilikte Kadına Yönelik şiddete ilişkin Tutumlar: Çelişik Duygulu Cinsiyetçilik, Yaş, Eğitim ve Gelir Düzeyinin Etkileri. Türk Psikoloji Yazıları,6 (11-12: 53-65.

\section{Turkish Studies - Social Sciences}

Volume 14 Issue 6, 2019 
Sakall1-Uğurlu, N. ve Akbaş, G. (2013). Namus Kültürlerinde "Namus" ve "Namus adına KadınaŞiddet": Sosyal Psikolojik Açıklamalar. Türk Psikoloji Yazıları,16 (32), 76-91.

Sallan-Gül, S. ve Altındal, Y. (2015). Medyada Kadın Cinayeti Haberlerindeki Cinsiyetçi İzler: Radikal Gazetesi. Akdeniz İletişim Dergisi, 24, 168-188.

Sallan-Gül S. (2014 ). Türkiye'de Kadına Yönelik Aile İçi Şiddet ve Yoksulluk Arasındaki İlişkiyi Sorgulamak. Abdullah Topçuoğlu, Gamze Aksan ve Duygu Alptekin (Ed.), Yoksulluk ve Kadın içinde (ss. 89-128). İstanbul: Ayrıntı.

Sen, P. (2014). Namus Suçlar1, Anlam ve Önemi.L.Welchman \& S. Hossain (Eds.). 'NAMUS' Suçlar, Paradigmalar ve Kadına Yönelik Şiddet içinde (çeviren: M. Tabur, A. Sönmez, C.Tanır ve S. Şekercan) (ss.59-78). İstanbul: BGST Yayınları.

Sev'er, A.,\& Yurdakul, G. (2001). Culture of Honor, Culture of Change. Violence Against Women, 7(9): 964-998. doi:10.1177/10778010122182866

Tahincioğlu, A. N. Y. (2011). Namusun Halleri. İstanbul: Postiga Yayınları.

TBMM Komisyon Raporu (2015). Kadına Yönelik Şiddetin Sebeplerinin Araştırılarak Alınması Gereken Önlemlerin Belirlenmesi Amactyla Kurulan Meclis Araştırması Komisyonu Raporu. 1. Cilt, Sira Sayısı: 717

TBMM Komisyon Raporu (2006). Töre ve Namus Cinayetleri ile Kadınlara ve Çocuklara Yönelik Şiddetin Sebeplerinin Araştırllarak Alınması Gereken Önlemlerin Belirlenmesi Amacıyla Kurulan (10/148, 182, 187,284, 285), Esas Numaralı Meclis Araştırması Komisyon Raporu. Sira Sayıs: 1140.

Tezcan, M. (1999). Ülkemizde aile içi töre ya da namus cinayetleri. T.C. Başbakanlık Kadının Statüsü ve Sorunları Genel Müdürlüğü içinde (21-27). Ankara: T.C. Başbakanlık Kadının Statüsü ve Sorunları Genel Müdürlüğü

Tomul, E. (2007). Türkiye'de Eğitime Katılım Üzerinde Gelirin Etkisi. Pamukkale Üniversitesi Eğitim Fakültesi Dergisi, 2(22): 122-131.

Ünsal-Atan, Ş. (2016). Töre ve Namus Cinayetleri. Türkiye Klinikleri 2(2): 67-73.

Yaman-Öztürk M., Dedeoğlu S. (2010), “Kapitalizm ve Ataerki İlişkisi Çerçevesinde Kadın Emeği”, Kapitalizm Ataerkillik ve Kadın Emeği (Türkiye Örneği), Sosyal Araştırmalar Vakfı Yayınları, İstanbul, Derleyen: Saniye Dedeoğlu, Melda Yaman Öztürk

Vandello, J. A. (2016). Do We Need a Psychology of Women in the Islamic World?' Sex Roles, 75: $623-629$.

Vandello, J. A. ve Cohen, D. (2003). Male Honor and Female Fidelity: Implicit Cultural Scripts That Perpetuate Domestic Violence. Journal of Personality and Social Psychology, 84: 997-1010.

Yıldırım, A. ve Şimşek, H. (2005). Sosyal Bilimlerde Nitel Araştırma Yöntemleri (5. Baskı) Ankara: Seçkin.

Yıldız, A. N. (2009). Kadın Cinselliğinin Söylemsel İnşası ve Namus Cinayetleri: Şanlıurfa Örneği (Yayımlanmamış Doktora Tezi). Ankara Üniversitesi Sosyal Bilimler Enstitüsü. Ankara.

Zeyneloğlu, S., Kısa, S., ve Y1lmaz, D., (2013). Turkish Nursing Students' Knowledge and Perceptions Regarding Virginity. Nurse Education Today, 33(2): 110-115.

https://insamer.com/tr/kadina-yonelik-siddetE.T. 25. 09. 2019

http://www.cumhuriyet.edu.tr/ogrenci/index.php?Dil=1\&d=410 